\section{INNOVATION AWARD 2012}

\section{Pipelife Austria als innovativstes Unternehmen und Qualitätspionier ausgezeichnet}

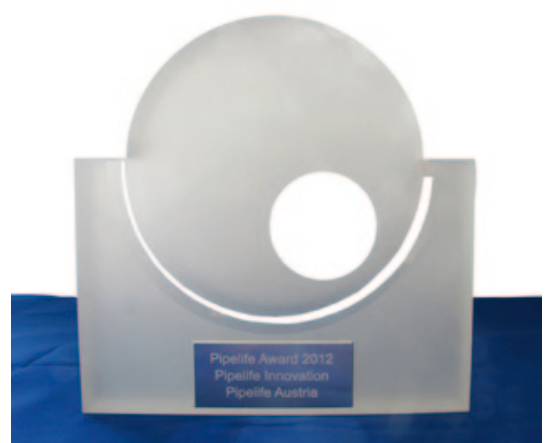

Gleich zwei neue Awards für Pipelife Austria: Der „Innovation Award 2012“ ...

Im zweiten Quartal 2013 konnte sich der größte österreichische Kunststoffrohrproduzent gleich über zwei Auszeichnungen freuen. Im Rahmen der Annual Conference von Pipelife International im Juni 2013 in Tallinn (Estland) wurde Pipelife Austria mit dem „Innovation Award 2012“ der in 27 Ländern tätigen Gruppe ausgezeichnet. Der Preis wird an jenes Unternehmen vergeben, das den höchsten Anteil an Produktsortimenten, die nicht länger als fünf Jahre am Markt sind, aufweist.

Erst kurz davor war Pipelife Austria als erster österreichischer Kunststoffrohrhersteller von Quality Austria für 20 Jahre durchgängig erfolgreiche ISO9001-Zertifizierung als "Qualitätspionier“ ausgezeichnet worden. Den Award verleiht Quality Austria an Unternehmen,

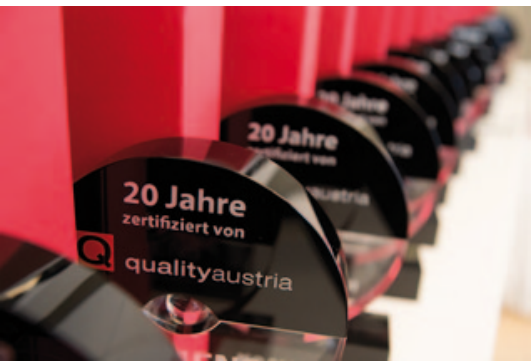

und die Auszeichnung als "Qualitätspionier" (Fotos: Pipelife).

die zertifiziertes Qualitätsmanagement seit 20 Jahren als fixen Bestandteil ihrer Unternehmenspolitik sehen und durchgängig danach zertifiziert sind. Er steht für Weitblick bei den Kundenbedürfnissen, Durchblick für die optimale Gestaltung von Prozessen, die Integration neuer Anforderungen, das richtige Augenmaß, genaues Hinsehen sowie die partnerschaftliche Zusammenarbeit mit Kunden auf Augenhöhe.

Pipelife Austria bietet komplette Systemlösungen für viele Bereiche des Lebens an. Kernkompetenzen sind dabei die Entwicklung und die Produktion von Rohrsystemen für die verantwortungsvollen Bereiche Wasserversorgung und $\mathrm{Ab}$ wasserentsorgung.

Bei Pipelife kommt ausschließlich höchste Rohstoffqualität zum Einsatz und es kommen modernste Technologien zur Anwendung. Die Produkte werden permanent weiterentwickelt und genügen den höchsten Ansprüchen.

So erfüllen beispielsweise PipelifeKanalrohre die Anforderungen des GRISGütezeichens: für PE-Rohre GRIS 110, für PE 100 und PE 100-RC GRIS 167, für PP-Mehrschichtrohre GRIS 146 und für PVC-Rohre GRIS 111. Das Gütezeichen bestätigt für Abwasser die Konformi-

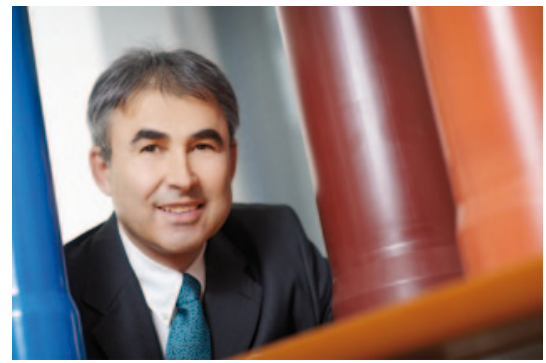

Pipelife-GF Mag. Karl Aigner: „Wir bieten unseren Kunden innovative Systemlösungen in Top-Qualität für nachhaltige Investitionen." (Foto: Andi Bruckner)

tät mit den ÖGA (Österreichische Güteanforderungen für Erzeugnisse im Siedlungswasserbau). Neben den hohen technischen umfasst die GRIS-Qualitätsmarke kundenspezifische Anforderungen wie Verfügbarkeit, Kundenberatung, Baustellenbetreuung, Versicherungsnachweis, Qualitätsmanagement, Materialrücknahme, Vertretung in Österreich sowie Entsorgung und Recycling. Das bedeutet geprüfte Qualität, die weit über die Anforderungen einer ÖNORM hinausgeht. Bei diesen Produkten können PlanerInnen und AuftraggeberInnen sicher sein, sinnvoll zu investieren.

Informationen:

Pipelife Austria GmbH \& Co KG

IZ-NÖ-Süd, Straße 1

2355 Wiener Neudorf

Tel. + 43-2236-6702-0

www.pipelife.at

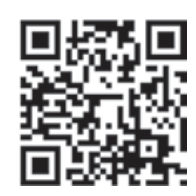

